\title{
Spider Flower
}

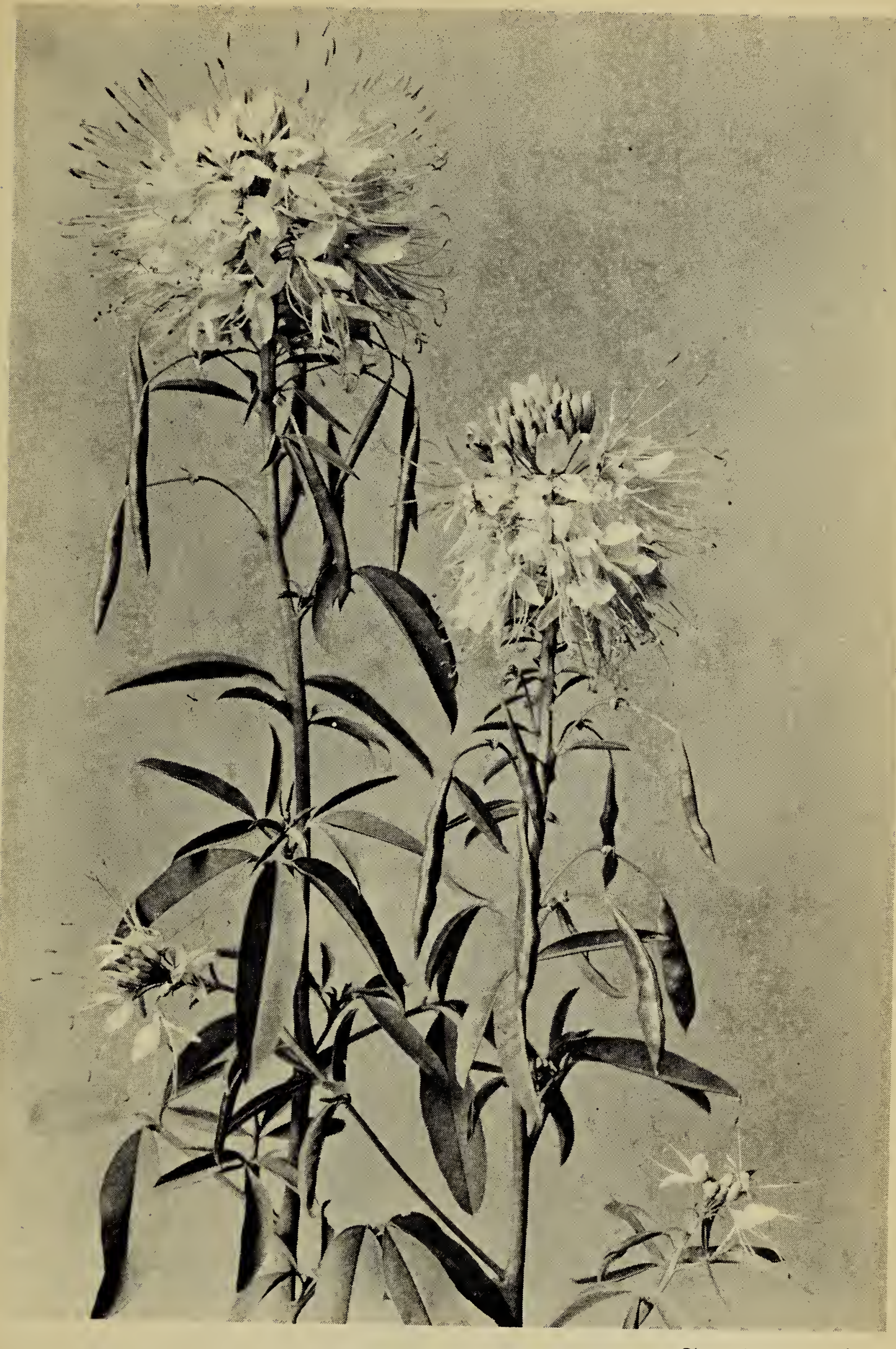

Cleome serrulata Pursh

Photo by W. C: McCallo

The spider flower, or bee plant as it is sometimes called, is an annual, one to three feet tall. Leaves are dividedl into three leaflets and the flowers are usually pink. Each flower has six longl exserted stamens and the fruits are stipitate. The plants prefer sandy places and in good years they may be very conspicuous along some roodsides. 